\title{
End of another year: a time of reflection and a time to thank Editorial Board members, authors and reviewers
}

\author{
LA Harvey \\ Sydney, Australia \\ E-mail: spinalcord@iscos.org.uk
}

This December 2017 edition marks the end of my first year as Editor-in-Chief of Spinal Cord. It is therefore a time of reflection and a time to thank the many people who have contributed to the success of the journal over the year. There have been many changes in 2017 which reflect the change of guard, the change in the role of the Associate Editors and the change to our Editorial Board. Some of the changes are procedural which would not have been noticed but other changes are fundamental to the publication direction and priorities of Spinal Cord.

The most important but perhaps silent change has been to the role of the Associate Editors. The journal's four Associate Editors (Marcel Post, John Steeves, Sonja de Groot and Masaya Nakamura) have taken on the role of handling manuscripts. They oversee the review process and make high level recommendations about publication. This has been a very positive move for the journal because it ensures that we have the necessary breadth of content expertise to cover the range of papers we receive. It also helps to ensure that we widen our pool of reviewers through our combined professional and academic networks.

The Editorial Board has also seen changes with many new faces. The new Editorial Board brings a wealth of clinical and academic experience to the journal. They all work very hard in an effort to ensure that every manuscript is reviewed by at least one member of the Editorial Board. In addition, and perhaps unbeknown to authors, members of the Editorial Board often make initial recommendations about whether a manuscript should move through the review process. In this way, the important responsibility of deciding whether a manuscript is considered for publication, is spread across many different people. My job is to oversee this process and ensure good and fair decisions. However, my job is made much easier with the loyal and excellent support of the Editorial Board. To all of them we owe a very big thanks.

Of course, the quality of a journal is very dependent on three major contributors: authors, readers and reviewers. Authors have continued to show their support to the journal with an ever increasing rate of submissions. We thank all our authors and hope that they will continue to choose Spinal Cord as their preferred place of publication. We particularly congratulate the authors of the two papers published in 2016 that were recently awarded the "Readers' Choice" (one overall winner and one winner for original research). This award was based on the number of downloads in the first six months since publication. The two winners were:

- P Boadas-Vaello, S Castany, J Homs, B Álvarez-Pérez, M Deulofeu and E Verdú. Neuroplasticity of ascending and descending pathways after somatosensory system injury: reviewing knowledge to identify neuropathic pain therapeutic targets. Spinal Cord 2016; 54, 330-340; doi: 10.1038/sc.2015.225.

- H E Marei, A Althani, S Rezk, A Farag, S Lashen, N Afifi, A Abd-Elmaksoud, R Pallini, P Casalbore, C Cenciarelli and T Caceci. Therapeutic potential of human olfactory bulb neural stem cells for spinal cord injury in rats. Spinal Cord 2016; 54, 785-797; doi: 10.1038/sc.2016.14.

All submitted manuscripts are massaged and jollied into a higher state of being by the many reviewers who silently work behind the scenes. Probably, most authors would like their manuscripts to sail through the review process untouched and unmarked. However, the peer review process is central to academia and publication. It ensures high quality papers and it should be seen by authors as a welcomed opportunity to iron out any blemishes and get valuable feedback on their work from their peers. Our reviewers are very diligent. In 2017, we used the services of over 300 different reviewers. We extend our sincere thanks to all of them and hope that they and others will continue to review for us.

There have been a number of other changes and achievements over the year including:

- the launch of our new website with a modern banner which better reflects the scope of the journal

- a $20 \%$ increase in our impact factor to 1.87

- the refinement of our publication priorities. These are now outlined in our new instructions to authors

- the introduction of plagiarism checks on all manuscripts

- the insistence that all clinical trials are registered

- our continued encouragement of data sharing

- authors' better adherence to the various reporting guidelines

So as we move into 2018, please feel free to drop me a line, provide suggestions and give feedback to help further develop our journal. But most importantly, continue to read, support and submit papers to Spinal Cord. Many thanks to all.

Spinal Cord (2017) 55, 1045; doi:10.1038/sc.2017.108 